\title{
Mothers' Attitude to Giving Sexuality Education as a Check to Sexual Abuse of Primary School Girls in South-East Nigeria
}

\author{
Dr. Nkiru Ohia \\ Institute of African Studies, University of Nigeria, Nsukka \\ nkiru.ohia@unn.edu.ng
}

\section{Doi:10.5901/jesr.2016.v6n1p133}

\section{Abstract}

\begin{abstract}
In South-East Nigeria, otherwise known as lgbo land, girls are inadvertently exposed to sexual abuse. This is because of the wrong notion that ignorance of sexual issues by young people promotes chastity. Ironically, due to the same ignorance, many primary school girls are sexually abused by peers, teachers and relatives thereby exposing them to psychological trauma, unwanted pregnancies, physical injury, sexually transmitted diseases and abandonment of babies. This study sought to find out the attitude of mothers towards giving Sexuality Education as a tool to minimizing sexual abuse of primary school girls. Three research questions guided the study. A multi-stage purposive sampling technique was used to first sample 2 states, 4 Local Governments, 8 towns and 160 women in South-East Nigeria. The instrument for data collection was a Focus Group Discussion Schedule based on the purpose of study and research questions. Data collected were qualitatively analyzed.Results show that there is high prevalence of child sexual abuse, mothers do not know what constitute Sexuality Education, and there is fear that Sexuality Education promotes promiscuity. Some recommendations were made bearing in mind the findings of the study.
\end{abstract}

Keywords: Sexual abuse; Sexuality education; Culture; Children; Women,

\section{Introduction}

Sexual abuse of children is forcing children to engage in sexual activity. This can range from kissing, touching of the sex organ to forced intercourse. Madunagu, (2007) defined child sexual abuse as any forced sexual contact on a child by an adult, while Karen \& Talon (nd) saw it simply as maltretment that involves a child in sexual activity to provide gratification to the perpetrator. Mitchell (2010) opined that it is all forms of unwanted fondling, forced anal or oral contact, sexual acts which are the result of coercion for food, clothing, shelter or employment. For the purpose of this study, sexual abuse of children is operationally defined as any sexual action with a child by an adult, or an older child which include;

- Oral or anal sex;

- Touching intimate parts of the body of children, whether clothed or not;

- Encouraging children to engage in sexual activity, including masturbation;

- Showing pornography to a child or using a child to create pornography;

- Encouraging a child to engage in prostitution and finally,

- Rape.

Child sexual abuse, like all matters relating to sex and sexuality is surrounded by a culture of silence and is rarely reported, although there is evidence to show that this injustice against children occure on a daily basis. Nearly all sexual abuse offences are commited by males but men and boys could also be victims of sexual abuse. Although what constitute a normal way of life in one culture may be frowned at in another, sexual abuse of children is unaccepted in all cultures. Culture according to Akubue \& Okolo (2008), is what is socially learned, socially shared and socially transmitted from one generation to another.

Child sexual abuse is so widespread that Kee, \& Bulkey (1982) noted that one in every ten girls is or have been sexually abused. They also revealed that $75 \%$ of girls who engage in sexual activity before the age of fourteen had been abused sexually. Most of the reported cases of child sexual abuse were commited by people who are well known to the victim. For example, Ebihuomhan (2014) reported of a 47 years old teacher in Edo state who was prosecuted for sexually harassing and raping a 12 year old girl in his class and another case involving another 47years old man who repeatedly raped his 12 years old daughter. While documenting reported cases of sexual abuse and rape of children, NTA (2007) reported an incident where a man was having carnal knowledge of his two daughters aged below 12 years, 
and threatened to kill them if they mentioned it to anyone. In another report by NTA (2007), a 39years old headmaster raped his pupil in the school's library; a teacher raped his 4years old niece ; a 45years old man raped a girl of 8years and a Deeper Life pastor raped his landlord's 3years old daughter. Documenting cases of child rape in some states, Ebihuomhan (2014) revealed that there were more than 51 reported cases of child rape in Enugu State between April and August 2014, in Edo, more than 80 cases in ten months, an average of 10 per month in Jigawa, and 427 cases in Lagos in 2012. Child sexual abuse and rape is so much on the increase that the Nigerian Senate in April 2015 passed a bill that prescribed life imprisonment for those who rape or have sexual intercourse with children below 13 years

Wood \& Jewkes (1997) in an earlier study on rape and sexual coercion of children, found that $51 \%$ of children between 6 months and 14years recieveing treatment for sexual abuse were abused by either a neighbour, a relative, a vistor to the house or a teacher.

Sexual abuse of children is frowned at because the victims are too immature to comprehend the actions meted to them, and are unable to give informed consent or disapproval. Unlike victims of sexual harassment, victims of child sexual abuse are so sexually immature that they do not possess the social power to resist or avoid it. Child sexual abuse is an infringement on the fundamental human rights of the child as most children abused have been victims of teenage pregnancy, sexually transmitted diseases, HIV and AIDS. Infact, Azikiwe \& Ohia (2009), in a study that sought to know the effect of sexual harassment on teaching and learning found that emotional instabillity, traumatization, and desire for more sex are some of the effects of sexual harassment. These in effect, may make a child lose the oppurtunity of schooling even when education is a fundamental human right of every Nigerian child. This is more so as in many instances, ignorant men rape children in the belief that unprotected sex with virgin girls would cure HIVIAIDS (Treger,2002), thereby voilating their right to the principle of life, survival and development to the highest attainable standard of health. Treger's view supports the Social Learning Theory of rape that links cultural traditions, sex-violence linkages, rape myths and desensitization to the core causes of rape. This theory suggests that rape, sexual abuse and other sexual violence against women and girls is common because of the societal attitudes, norms, and practices. Also the media seems to condone, normalize, and encourage sexualized violence by portraying a sexually aggressive man as a superman. This study is hinged on the feminist position on rape as suggested by Andersson \& Swainson (2001) as a gender- based violence against women, a crime that has nothing to do with sex itself. This is more so as an under aged child does not have any sexual attributes that could be said to attract a healthy man. Child sexual abuse is a conscious process of intimidation by which the perpetrator keeps the victim in a state of fear and subordination. However, no matter how sexual abuse is seen, the bottom line is that sexual harassment violates human rights and should be vehemently objected to.

Parents have the resposibility to their children in child rearing, upbringing, protection, and education which includes sexuality education. Hence, there is the need that parents give Sexuality Education early enough to their children but research evidence show that parents tend to shy away from this responsibility thereby leaving it to uninformed peers and even househelps (Dienye,(2011); Godswill,(2012) and Obiekea, Ovri and Chukwuma ,2013).

The reason for this is that in Igbo culture, parents never discussed sex or sexuality matters with their children, although mothers may allude to it but they do not talk about sexual matters with them. In the traditional setting Sexuality Education was given to girls as they undergo rites of passage at the onset of puberty by elderly (usually menopausal) aunts or designated sexuality teachers. During these rites, girls were taught how to take care of themselves, taught about marriage, child-birth and menstruation. They were taught how to 'comport' themselves during their periods and how to use menstrual cloth. They were also taught how to please their husbands when they get married, not to be overtly offended by their husband's sexual escapades with other women, and never to refuse them sex except during menstruation. Most importantly, they were taught that sex for women was solely for procreation and not for enjoyment, and never to gossip about their husbands' sexual behavior (discussion with an octogenarian, Ndumene Nwaezeakpa).

As the communal nature of the Igbo society is giving way to more nuclear one due to movement to townships, there is the need that as the previous arrangement of giving this education by the extended family members no longer holds, parents, especially, mothers have to take on this duty but research shows that many mothers are unwilling to embark on this duty. Laying credence to this view, Henslin (2002) averred that socialization and culture influences are so strong that many people find it difficult to shift from the norm. This attitude of parents may have contributed immensely to experimentation and risky behaviour among school children.

Many studies have identified Sexuality Education as a panacea to child sexual abuse (Omeje \& Nwosu 2007, Omeje 2009, and Okafor \& Agbonna 2010). These defined Sexuality Education as that aspect of education which helps individuals understand and prepare for those experiences in life that deal with the physical, emotional, social growth and 
maturation pertaining to sexuality and family life (Omeje \& Nwosu (2007); Obanor \& Omoera (2009) and Schidt,Abraham, \& Kimberly 2015 ). It is the orientation given formally or informally for the purpose of making those receiving it develop the right attitude towards all sex related matters in human relations. While Sexuality Information and Education Council of the United States (SIECUS) defined Sexuality Education as giving the right information on biological facts of the human body and the basic principles of wholesome human relationships, Obanor \& Omoera (2009) saw it as a lifelong process of acquiring information and forming attitudes, beliefs and values about identity, relationships and intimacy.

It is worth mentioning that the aim of Sexuality Education, according to Action Health Incorporated (1996:7) include:

- Development of interpersonal skills that include decision making, assertiveness and refusal skills;

- Helping children form attitudes in other to develop their their own values,to enhance self esteem,and to develop insights concerning sexes and relationships with members of both sexes and understand their obligations and responsibilities to others and,

- Helping children on how to resist pressure to become prematurely involved in sexual matters.

Hence,the concern of the researcher is to assess mothers' attitude to giving sexuality education to their daughters as a check to sexual abuse of primary school girls. Such assessment will provide information on the prevalence, teachings that constitute sexuality education and when sexuality education will commence.

\section{Statement of the Problem}

Although children are confronted everyday by sexuality in movies, television shows and books, Sexuality Education and services to young girls remain controversial issues in Nigeria and Igbo land in particular. This is due to the belief that ignorance of sexual matters encourages chastity, but newspaper reports and research findings show that girls are exposed to sexual abuse sometimes, even before they start attending school, thereby making them victims of sexually transmitted diseases and HIVIAIDS. To avert such problems, parents, particularly mothers have enormous roles to play in this regard since the home of the child is the first school of socialization. There is, therefore, the need that parents socialise their children early enough to at least let them know when somebody touches them "in a bad way" but it is observed that the strong influence of culture and religion seems to make open discussion of sex related matters a taboo and so, parents seem to shy away from their responsibility when it comes to discussions around sexuality. Consequently, parents who are supposed to be the primary sexuality educators to their children shirk from this responsibility leaving them to be educated by their equally uniformed peers, and the media. The problem of this study therefore, is to put up an investigation into the attitude of mothers toward giving Sexuality Education as tool for putting a check on sexual abuse of primary school girls.

Specifically, the study aimed at

1) Finding out the prevalence of sexual abuse of the girl child;

2) Identifying the teachings that constitute Sexuality Education;

3) Ascertaining if and at what age Sexuality Education should be given.

\section{Research Questions}

1) What is the prevalence of sexual abuse of the giri child?

2) What are the teachings that constitute Sexuality Education?

3) Should Sexuality Education be given and when should it be given?

\section{Method}

This study is a survey and was done using mothers who took part in the 2013 annual women summit (August meeting ) in two states, Enugu and Abia states out of the six states that make up South-East Nigeria. The exclusive use of these two states is informed by the notoriety of these two states in the activities of 'baby factories' where adolescent girls with unwanted pregnancies give up their babies for sale. In each of the states, quota sampling technique was used to sample two local governments, and in the Local governments, two towns were sampled thus, a total of eight towns were used in the study. In the towns used for the study, the Executives of women summits were approached during Executive Meetings prior to the August Meetings, briefed on the need for the study, and requested to be allowed to interact with some of the women that will be present at the August Meetings. The towns that failed to grant the request due to 
exigencies of time were replaced. Twenty women (in attendance at the meetings) were randomly sampled in each of the towns to ensure that both educated and not so well educated, urban and rural dwellers, young and middle aged mothers were included in the study. A total of 160 women participated in focus group discussions. The average duration of the discussion was 90 minutes of one session. The instrument used for data collection was a focus group discussion schedule which was developed based on the purpose of the study and the research questions. Two female post graduate students who were briefed on the aims and objectives of the study worked as Research Assistants. The guideline included:

1. Sharing experiences or stories of childhood sexual abuse experiences;

2. Meaning of Sexuality Education;

3. Whether Sexuality Education should be given;

4. Who should give Sexuality Education, and at what age?

Before the discussions commenced, the researcher explained the need for the study based on the increasing incidence of sexual abuse of the girl child, teenage pregnancies and sale of babies. After this, a focus group discussion was held with the discussants by the researcher with the help of the research assistants who helped to record the discussions. Data collected on tapes were transcribed and qualitatively analyzed.

\section{Results}

\subsection{Research question 1}

The first research question sought answers to the prevalence of sexual abuse of primary school girls. The discussants were asked if they have ever heard of, or were victims of child sexual abuse themselves. Almost all the discussants have heard about cases of child sexual abuse. Those who were victims said that they did not realize that the actions meted on them then was sexual abuse. As children, they thought it was just a kind of play with adult males, or older children (male and female). All those who reported being victimized as children said that it was much later that they realized what the actions meant. Below are some of the experiences shared by the discussants.

\section{Discussant I}

"There used to be a boy (Augustine) that lived with his master(Teacher) in our neighborhood. He was fond of carrying me on his laps. Each time he carried me, there used to be this hard thing between his legs that press on my buttocks that kept me uncomfortable. While carrying me, he used to touch my private part. As this will be going on, he will be giving me sweet or biscuits. Although I used to be uncomfortable and did not like what he does to do me, the biscuits and sweets he gives me made me go to him again each time he calls me".

\section{Discussant II}

"One Miss (a female teacher) lived in our yard and I used to do little chores like washing plates and sweeping the house for her. There was a time her brother visited. Each time Miss went to school, he will call me on the pretence that he wants to send me on an errand. When I get into the room, he will will be showing me erotic pictures in 'Drum' magazine. He tells me that he does the things in the magazine with Miss and will like to teach me to do it when I grow up. Actually, he did not for once touch me in a bad way but those pictures and the things he used to tell me aroused my intrest in sex quite early in life".

\section{Discussant III}

\footnotetext{
"When I was eight years old, precisely in 1977, not many people owned television sets. Only our landlord had one in the whole block. In the evenings, especially on Tuesdays, that was when they used to do show a soap opera called 'The Masqurades' (Zebrudaya), we go to watch television in the landlord's house. One day, there was a scene of a man and woman cuddling each other and I was so excited and announced to the crowd that our teacher does that to me and the other girls in the class. Because I believed that whatever our teacher did was right, I did not know that carrying me on his laps and touching me intimately when I go to drop the class register in his house was wrong. It was the beating Mama gave me, and her visit to the headmaster and the sudden transfer of the teacher that gave me an idea that something was wrong".
} 


\title{
Discussant IV
}

\begin{abstract}
"Actually, this did not happen to me nor any of my girls. My husband is a police man. One day, he came back from work and and told me to be very vigilant where my girls are concerned. I became confused because my eldest girl was just eight years old then. I then demanded know what he meant and he narrated how they investigated the case of a man that teaches in a nursery/primary school in Ifo Local Government Area of Ogun State, who was caught having carnal knowledge of one of his pupils. He said that the teacher confessed to have done it tomany other pupils whose ages range between seven and twelve"
\end{abstract}

\subsection{Research Question II}

Research Question II sought answers on what teachings constitute Sexuality Education. Nearly all the discussants thought that it is just teaching how to engage in sexual intercourse. Just one teacher in one of the groups said that it is teachings that have to do with teaching children how to take care of their bodies so that they can function well as adult men and women. Below are some of their contributions.

\section{Respondent $\mathrm{V}$}

"We all went to school but nobody taught us how to engage in sexual intercourse during our own time. We were only taught that getting too close to the opposite sex portend trouble and should be avoided"

\section{Respondent VI}

"In my own little understanding, I think that it is teaching children the functions of the different parts of their bodies and how to take care of them. At least this is what I try to do. I am a teacher and the authourities have been talking to us about this. It was not there during our own time. Even if we were molested or abused, we did not understand what it meant. Telling children the whole truth as it is, is not dangerous considering the fact that they already have experience from what they see on television".

\section{Discussant VII}

"Whether Sexuality Education or Sex Education, all of them mean that somehow you will tell a child the truth about getting pregnant and having babies. During our own time, the half truths we were given was enough education. Children were taught that they see with their eyes and should not put sharp objects in thier eyes. They are taught to clean their teeth so that they dont get bad. If children are also taught what their sex organs are for, it will be good.

\subsection{Research Question III}

This research question dealt with finding out at what age Sexuality Education should be given. Many discussants felt that this education should not be given at all because they will not be comfortable discussing such a sensitive matter with their daughters and that such teachings may cause the children to experiment on sex. The discussants who were in favour of giving Sexuality Education were of the opinion that it should be given when the child is about getting married, some said that the best time to start should be at the onset of menstruation. Some of their contributions include the following:

\section{Discussant VIII}

"There is no need asking when this teaching should be given because I will not sit my daughter down to tell her to go to bed with her husband. Nobody taught me. These things come naturally".

\section{Discussant IX}

"The only education we were given during our own time was how to keep our homes ,obey our husbands, and relate well with our in-laws. The other one should be left alone. As children are growing they will understand. After all unlike us, they now have things to read". 


\title{
Discussant $\mathrm{X}$
}

"I think that it is good to start early to demystify matters relating to sexuality. If Sexuality Education starts very early,it makes a child to discuss freely with the parents if somehow something goes wrong".

\section{Dicussant XI}

"It will be embarassing to engage my children in such discussion. If it has to be done at all, let their teachers do it".

\section{Discussant XII}

\begin{abstract}
"We have to let the sleeping dog lie at least untill the girls start mensurating or at best, when they are getting married. It is true that I was a victim as a child but because I did not understand, it was not much of a problem. Telling them about this when they are too small may make them to be inquisitive".
\end{abstract}

\section{Discussion of Findings}

Result of research question I indicated that there is a high prevalence of child sexual abuse. This is because every participant in the focus group discussion has heard stories of child sexual abuse or was once a victim, although without realizing it then. The findings from this research question also revealed that the abuses were perpetrated by people who were well known to the child and her family.

This finding is in line with the findings of Adeosun (2010) in a study to ascertain the prevalence of child sexual abuse in which he found that $52 \%$ of discussants confirmed having experienced sexual abuse. Also, Woods \& Jewkes (1997) found that $51 \%$ of children between 6 months and 15 years receiving treatment as a result of sexual abuse, were abused either by a neighbor, a visitor to the house, a relative or a teacher. The findings from research question I also revealed that experience of sexual abuse during childhood encourages premature interest in sexual activity. This finding corroborates the findings of Wood, \& Jewkes (1997) in a study conducted on child sexual abuse in rural populations of South Africa. Their study found that there is a positive correlate between risky sexual life and premature sexual activity and child sexual abuse. In another study to ascertain the relationship between child sexual abuse and sexually active primary school girls, Larsen, Chapman \& Armstrong (1996) found that $49 \%$ of the sexually active primary school girls reported having been sexually coerced and abused. Likewise in a related study, Trocme \& Wolf (2001) found that there is a positive relationship between sex abuse and precocious sexual activity like exhibiting seductive behaviours. Also, Tieno (1992) cautions that denying Sexuality Education, to young people may lead to experimenting in sexual actions which may result in undesirable consequences.

Findings from research question II show that many mothers, themselves, do not know the teachings that constitute Sexuality Education. This is probably because of the culture of silence on sexuality and sex related matters, and the misconception that sexuality is equivalent to coitus (Olanrewaju in Etego \& Oduyoye, 2013).

Research question III findings show that many mothers are not in favour of giving sexuality education. Their stand may probably be as a result of religion and culture which teach that sexuality matters, if discussed at all, should be between husband and wife, and behind closed doors. The findings further show that the mothers who were in favor of giving Sexuality Education feel that it should be given at first menstruation or when the child is about getting married. If human sexuality is portrayed as a healthy normal part of life that is not derogatory, there should be no need delaying such important aspect of education. The need for early exposure to Sexuality Education is even more expedient now that the Nigerian Senate has passed a bill that inadvertently makes 11 years the age of sexual consent in Nigeria. Again, there is research evidence (Godswill, 2012; Unesco,2014; Konwea and Mfrekemfon 2015) that many children are now sexually active even before they start menstruating and are also ignorant of the fact that they can get pregnant after just one exposure to intercourse.

\section{Conclusions}

The following conclusions were made based on the findings of the study:

- There is a high prevalence of child sexual abuse. This could be because abusers are not visited with stringent penalties. Most times they will be made to pay a fine or may be allowed to go away with it. This is even more so as families of victims do not come out fully to fight the injustice due to fear of exposure and stigmatization. 
- Many mothers do not know what constitute Sexuality Education. Due to the change in the society, many mothers themselves did not receive sexuality education as was given in the traditional societies. They are the generation that received Western Education which did not do so much in giving Sexuality Education.

- Many mothers express the fear that Sexuality Education promotes promiscuity.

\section{Recommendations}

Based on the findings of the study, the following recommendations were made.

- There should be massive re-orientation programmes, seminars and symposiums involving the church, NGOs, traditional rulers and women associations to help change the misconceptions about Sexuality Education.

- Sexuality Education should be included in primary and secondary school curriculum and in the General Studies for undergraduates as the knowledge acquired will be beneficial to them throughout life.

- Parents, should be encouraged to understand that since the family structure is changing from extended to nuclear, those duties hitherto performed by extended relations have to be undertaken by them since failure to do so will amount to denying their children their right to comprehensive education.

\section{References}

Anderson, I. \& Swainson, V. (2001). Percieved motivation for rape: Gender differences in belief about female and male rape. Current Research in Social Psychology 8 (6). http//www.uiowa.edu-grppoc/crisp.6.8.html. Accessed January 12th, 2012.

Action Health Incorporated (1996). Guidelines for Comprehensive Sexuality Education in Nigeria. http/www.hivhealtclearinghouse.unesco.org/library/documents/guidelines-comprehensive-sexuality-education-nigeria.Accessed January $12,2012$.

Azikiwe, U. \& Ohia, N. (2009). Sexual harassment of secondary school girls: A stumbling block to teaching and learning. Nigerian Journal Of Sociology Of Education 3 (3) 22-35.

Akubue, F.N.\& Okolo, A.N. (2008) Sociology of Education. Nsukka: Great AP Express Publishers

Dienye,V.E.(2011). The educational and social implications of sexuality and sex education in Nigerian schools. African Journal of Social Sciences 1(2)11-19.

Ebhuomhan, U. (2014) Investigation: Inside Nigeria's growing rape epidemic. Premium times, November 22. Accessed from http://www.premiumtimesng.com/news/171717-investigation-inside-nigerias-growing-rape-epidemic.html.

Godswill, J. (2012). Education and sexuality: Toward addressing adolescents'reproductive health needsin Nigeria. Current Research Journal of Social Sciences 4 (4) 285-293.

Henslin, J.M. (2002) Essentials of Sociology: A down to earth approach. Boston: Allyn and Bacon. 312-317.

Imaobong U (2001). Taming child sexual abuse monster. Vanguard 17th November

Kareen J, \& Tallon, J (nd ) Child sexual abuse: A review of the literature http://www.childprotect.org/statisitics Retrieved 1st June, 2010.

Kee, F. \& Bulkley, J (1982). Treating child sexual abuse: An overview of current program models.Journal of Social Work and Human Sexuality 1(1) 69-91.

Konwea,P. \& Mfrekemfon, P.(2005). Parents perception of the teaching of SexualityEducation in secondary schools in Nigerie. International Journal of Innovative Science,Engineering and Technology 2(1) 88-99.

Larson,I., Chapman, J. \& Armstron, A. (1996). A child sexual abuse in rural populations. South African Medical Journal 86 (1) 1432 1433.

Madunagu, B.(2007). Girls trafficking: Challenges to sexual health, reproductive health and human rights. In Women Heaelth and Empowerment. Madunagu, Eand Akpan, J. eds. Calabar: Clear Lines Publications. 307-314.

Mitchell, M.W. (2010)Child sexual abuse: A school leadership issue. The clearing House: A journal of Educational Strategies,Issues and Ideas. 83 (3) 101-104.

Nigeria Television Authority (2007). AM Express Report on Sexuality Education. Thursday, February 16th.

Obanor, M and Omoera O. (2009). Refocusing Sexuality Education Among Nigerian Adolescents:The Theatre Option http://www.aaukpoma.edu.nis. Retrieved 1st June, 2010.

Obiekea, P., Ovri, F. \& Chukwuma, E. (2013). Sexual Education: An intervention and social adjustment programme for youths in secondary schools in Nigeria. African Research Review 7(1) 322-339.

Okafor, I. \& Agbonna S. (2010). Assessment and implications of the sexual attitude of Nigerian parents in Federal Capital Teritory, Abuja. In Book of Readings in Sociology of Education. A Publications of the Association of Sociologists of Education of Nigeria. I(1) $16-21$.

Olanrewaju, D.O. (2013) The menace of rape and its implications for the girl child from the religious ethics perspective: Lagos State as a case study. In Etego and Oduyoye ed.(2013). Religion and Gender Based Violence: The West African Experience. Ghana: Lagon Theological Studies Series 234-262.

Omeje, J. \& Nwosu, E. (2007). Sexuality Education and the role of women in training of schooling adolescents: Implication for effective 
service delivery. In B.G. Nworgu (ed) Optimization of Service Delivery In the Education Sector: Issues and Strategies. Nsukka: Universal Trust Publishers

Omeje,J. (2009). Inclusion of Family Life Education In school curriculum: Perceptions of parents and students in Nsukka Urban. International Journal of Educational Research 9 (1) 2009.

Sampson, O. (2010) Community to banish man for impregnating 18 years old daughter. Daily Sun Wed 29th December, P.10.

Schmidt, S.C, Abraham, W., \& Kimberly, J.H. (2015). Evidence-based Sexuality Education Program in schools: Do they align with National Sexuality Education standards?. American Journal of Sexuality Education 10 (2) 117-195.

Sexuality Information and Education Council of the United States (SIECUS). Current Information and Publicity on sexuality. http://www.siecus.org/pubs Retrieved 1st June, 2010.

Tieno, A. S. (1992). Off our backs: Sexuality and popular culture. New York: Gale Group

Treger,L.(2002).Community perceptions around cultural myths of girl child rape and HIV in the Northern Cape province of South Africa.http/gateway.nlm.nih.gov/MeetingAbstracts/ma?f=102254896.html.Retrieved 3rd November,2010.

Trocme, N. \& Wolf, D. (2001). Child maltreatment in Canada: Canadian incidence study of reported child abuse and neglect. Clearing House on Family Violence Health Canada.

UNESCO, (2014). Comprehensive Sexuality Education: The challenges and opportunities of scalling-up. Accessed on $15^{\text {th }}$ June, 2015 from www.unesdoc.unesco.org/images/0022/002277/227781E.pdf.

Wood, K \& Jewkes,R.(1997). Violence,race and sexual coercion: Everyday love in a South African Township. Gender and Development5 (2) 41-46. 